\title{
Epidemiological study on manage mite, lice and sheep keds of small ruminants in tigray region, northern Ethiopia
}

\author{
Enquebaher Kassaye* and Etsay Kebede
}

College of Veterinary Medicine, Mekelle University. P. O. Box 1118, Mekelle, Tigray, Ethiopia

* Corresponding author: enquebaher@yahoo.com

\section{Abstract}

Tigray Region used to be an important source of hides and skins in Ethiopia. However, today the quality and quantity have significantly declined, for which external parasites are incriminated as major causes. Epidemiological study on mange mite, lice and sheep keds of small ruminants was conducted, from Feb.-Aug./2003, with the objectives of determining the distribution and the major risk factors associated with the external parasites. A total of 43,325 animals (22,337 sheep and 20,988 goats), from lowland, medium and high altitudes, were clinically inspected, for the parasites during the dry and wet seasons. The prevalence rate of mange mite was $8.11 \%(95 \% \mathrm{Cl} 4.2284-4.6179)$ and $0.95 \%(95 \% \mathrm{Cl} 0.8303-1.0898)$ for goat and sheep, respectively. Goats were 9.17 (OR=9.17, 95\% 7.92-10.61) times at higher risk of acquiring mange mite infestation than sheep. Statistically significant difference $\left(X^{2}=121, P=0.0000\right)$ was observed during the dry $(5.68 \%)$ and wet $(3.48 \%)$ seasons which was associated with seasonal feed shortage and other stress factors. Animals in lowland were $2.63(\mathrm{OR}=2.6,95 \%$ 2.15-3.20) times more exposed to mange mite infestation than the highland. The prevalence of lice infestation in goats was $11.98 \%(95 \% \mathrm{Cl} 11.5466-12.4301)$. During the dry season, animals were exposed to lice infestation 2 times $(\mathrm{OR}=2.18,95 \%$ 1.51-1.77) more than in the in wet season. Statistically significant difference $(P<0.05)$ in lice infestation was recorded between lowland (6.89\%) and highland $(3.75 \%),<1$ year age $(7.19 \%)$ and $>2$ years $(5.53 \%)$ and male $(8.3 \%)$ and female $(5.28 \%)$. The Overall prevalence of sheep keds was $11.67 \%$. (95\% Cl 13.8833-16.0302) Statistically significant difference $(P<0.05)$ was also observed between highland $(19.48 \%)$ and lowland $(1.84 \%)$. Sheep in the highland were 13 times more at higher risk of acquiring sheep keds infestation than those in the lowland $(\mathrm{OR}=12.9,95 \% \mathrm{Cl}, \mathrm{OR}$ 10.77-15.44). Finally animal species, agro climatic conditions and seasons were the main risk factors considered during the study of the epidemiology, a knowledge which should be incorporated during control measures.

Keywords: Agro ecology, Epidemiology, Lice, Mange mite, Sheep keds, Small ruminants 


\section{Introduction}

Livestock is the main stay of the vast majority of Ethiopian people with large and small communities almost entirely dependant on this industry for economic stability. Among the livestock population, small ruminant constitute a major part. According to Tigray Bureau of Agriculture and Natural Resources (1999), the population of small ruminants of Tigray region is estimated at 935,349 sheep and $1,465,741$ goats. The productivity of small ruminants is constrained by many factors, among which, traditional husbandry practices, availability of poor quality and quantity feed and the presence of endemic and epidemic diseases are the major ones. Ethiopia is earning significant foreign currency by exporting skins and hides to international market. Export of pickled sheepskins and wet-blue goat skins are important sources for foreign exchange. According to FAO (2001) report, in 1995/96, Ethiopia earned USD 69.5 Million from export of skins and hides to the international market. Yibralem (2000) also reported that Ethiopia is capable of exporting 16 to 18 million of skins and hides to foreign market, annually. Tigray Region had been important source of skins and hides for the country. However, the quantity and quality of skins and hides supplied from Tigray region has significantly declined from time to time. Preliminary field survey results and tannery reports indicated that the main reason for this deterioration is skin diseases (FAO, 2001). Skin diseases such as mange mites, lice and keds infestation of small ruminants adversely affect the quality of skins and hides, which render them unfit for export purposes. However, the distribution, magnitude and the associated risk factors were not adequately studied. Therefore, the present study was undertaken to determine the overall epidemiology of the aforementioned skin diseases of small ruminants and the associated risk factors in Tigray Region, Northern Ethiopia. The findings of this study may help in understanding the epidemiology of the diseases and designing their control measures.

\section{Materials and Methods}

Project area: The study was conducted in Tigray Region, Northern Ethiopia, located between latitude $12^{\circ} 16^{\prime}$ and $12^{\circ} 55^{\circ} \mathrm{N}$ longitudes $39^{\circ} 22^{\prime}$ and $39^{\circ} 53^{\prime} \mathrm{E}$. According to Tigray Bureau of Agriculture and Natural Resources (1999) three agro climatic zones are identified in the region. Lowland: at an altitude of 5001500 meters above sea level (masl) and mean annual rainfall of $300-<600 \mathrm{~mm}$. Medium altitude: Having an altitude of 1500 -2300 masl with mean annual rainfall of $400->600 \mathrm{~mm}$. Highland: With altitude of $2300-3200$ masl and mean annual rainfall of $500-800 \mathrm{~mm}$. Generally, the study area is character- 
ized by dry and wet seasons: The dry season extended from February to May and the wet season goes from June to September with peak in August.

The study was conducted in eleven $(n=11)$ weredas (administrative unit) of the region, which were purposely selected as highly affected areas by the external parasites based on the wereda veterinary case book report. The affected weredas are classified into the aforementioned major agro climatic zones as follows:

Lowland: Kolla Tembene, Tanka Abergelle, Mereb Leke and Tahtaye Adyabo Weredas.

Medium altitude: Asgede Tsemebella, Laelay Adyabo, Samre-Sahrtie and Sasie-Tsaeda Emba Weredas.

Highland: Atsebie Wenberta, Ganta Afeshume and Offla Weredas.

Study designs: A cross sectional study conducted during the dry (February May/ 2003) and wet

(July-September/2003) seasons of the year.

Study population: Sheep and Goat were examined for the presence of the following external parasites.

Goats: for mange mites and lice

Sheep: for mange mites, lice and sheep keds.

Sample size determination: The sample size from each Wereda was determined by Epi Info 6, version 6.02 software statistics program, taking into consideration the small ruminant population of the selected weredas and the expected prevalence of the external parasites with the $95 \%$ confidence limits. During the two seasons a total of 43,325 small ruminants, 22,337 sheep and 20,988 goat were sampled (Table1). The determined sample size was taken from each Wereda using systematic random sampling method at village level using the EPI method. 
Enquebaher Kassaye, et al.

Table 1: Sample size taken during the two seasons

\begin{tabular}{llccc}
\hline & Season of the & \multicolumn{2}{c}{ Animal species } & Total \\
\cline { 3 - 4 } & year & Goat & Sheep & \\
\hline 1 & Dry period & 7,522 & 10,931 & 18,453 \\
2 & Wet period & 13,466 & 11,406 & 24,872 \\
& Total & 20,988 & 22,337 & 43,325 \\
\hline
\end{tabular}

\section{Study Methods:}

Mange mite: The sampled animals were clinically inspected for presence of mange mite. From animal showing signs of scales, crusts, alopecia itching, a skin scraping was taken by the following procedure. A drop of mineral oil was put on a clean glass slide, dip a clean scalpel in the drop and then scrape the edge of the affected area until blood oozed. The collected scrape samples were preserved in $10 \%$ formalin and dispatched to laboratory for further confirmatory examination.

Lice: The neck, shoulder, breast, ribs, back, flank and rump areas of both sides of the body were examined for presence of lice by parting the hair. From each site five partings of about $10 \mathrm{~cm}$ long were examined. From clinically positive animals, specimens were collected, preserved in $10 \%$ formalin and later identified /confirmed in the laboratory.

Sheep Keds

The neck, shoulder, flank, back, belly and rump of both sides of the animal body, were inspected for sheep keds using the parting system as indicated for lice examination. From clinically suspected animals specimens were collected, preserved and dispatched to laboratory for confirmation.

All collected samples were examined /confirmed in the laboratory as being mange mite, lice and sheep keds, as per the procedure recommended by Urquhart et al (1996).

During the aforementioned physical examinations the sex, the age group and the physical condition of each sampled animal was registered. Three age groups ( $<1$ year, 1-2 year and >2 year) were noted by dental formula as described by Aiello and Mays (1998). The physical condition of the inspected animals were also registered as good, moderate and emaciated based on the criteria obtained from the Tigray Bureau of Agriculture and Natural Resources (1999). The cri- 
terion based on the condition of muscles on backbone, hipbone, rib bone and tail head.

Data Analysis

Microsoft excel was used as database for the study. The Epi info 6, version 3.5.1 for windows (2008) statistics computer program was used for analysis of the data. Chi square and odds ration were used to describe differences, associations and degree of associations of different risk factors with the diseased.

$P<0.05$ was considered as statistically significant value.

\section{Results}

Mange mite:

The dominant type of mange mite identified was Sarcoptes scabies. However, rarely, the genus Demodex and Chorioptes were identified. In most cases, Demodex species were found mixed with Sarcoptes infestation.

The overall prevalence of mange mite in the small ruminant was $4.42 \%$ (95\% $\mathrm{Cl}$ 4.2284-4.6179). The point prevalence of mange mite in sheep was $0.95 \%$ (95\% Cl $0.8303-1.0898)$ and $8.11 \%(95 \% \mathrm{Cl} 7.7435-8.4869)$ in goat (Table 2). The infestation rate between the two animal species was statistically significant $\left(\mathrm{X}^{2}=1311.53, \mathrm{P}=0.0000\right)$. Odds ration analysis indicated that goats were 9.17 times exposed to mange mite infestation than sheep $(\mathrm{OR}=9.17,95 \% \mathrm{Cl}$ OR 7.92-10.61).

Seasonal prevalence of mange mite

The point prevalence of mange mite was $5.68 \%(95 \% \mathrm{Cl} 5.3549-6.0286)$ and $3.48 \%(95 \% \mathrm{Cl} 3.2574-3.7172)$ during the dry and wet seasons, respectively (Table 2). The difference was statistically significant $\left(X^{2}=121.68, P=0.0000\right)$. Goats in dry season of the year were 1.67 times exposed more to mange mite infestation than the wet season (OR=1.67 95\% Cl OR1.52-1.83). 
Table 2: Prevalence of mange mite of small ruminant in different season, agro climate, age and sex

\begin{tabular}{|c|c|c|c|c|c|}
\hline & \multirow[t]{2}{*}{ Risk Factor } & \multirow{2}{*}{$\begin{array}{l}\text { Total Exam- } \\
\text { ined animals }\end{array}$} & \multicolumn{3}{|c|}{ Mange mite } \\
\hline & & & Positives & Negatives & Percent prevalence (\%) \\
\hline \multirow[t]{4}{*}{1} & Animal species & & & & \\
\hline & Sheep & 22,337 & 213 & 22,124 & 0.95 \\
\hline & Goat & 20,988 & 1,702 & 19,286 & 8.11 \\
\hline & Total & 43,325 & 1,915 & 41,410 & 4.42 \\
\hline \multirow[t]{4}{*}{2} & Season & & & & \\
\hline & Dry & 18,453 & 1,049 & 17,404 & 5.68 \\
\hline & Wet & 24,872 & 866 & 24,006 & 3.48 \\
\hline & Total & 43,325 & & & \\
\hline \multirow[t]{5}{*}{3} & Agro-climate & & & & \\
\hline & Lowland & 16,755 & 922 & 15,833 & 5.5 \\
\hline & Medium & 21,507 & 883 & 20,624 & 4.11 \\
\hline & Highland & 5,063 & 110 & 4,953 & 2.17 \\
\hline & Total & 43,325 & & & \\
\hline \multirow[t]{5}{*}{4} & Age & & & & \\
\hline & $<1$ year & 9,486 & 314 & 9,172 & 3.31 \\
\hline & 1-2 year & 6,140 & 296 & 5,844 & 4.82 \\
\hline & $>2$ years & 27,699 & 1,305 & 26,394 & 4.71 \\
\hline & Total & 43,325 & & & \\
\hline \multirow[t]{4}{*}{5} & Sex & & & & \\
\hline & Male & 10,218 & 467 & 9,751 & 4.57 \\
\hline & Female & 33,107 & 1,448 & 33,107 & 4.37 \\
\hline & Total & 43,325 & & & \\
\hline
\end{tabular}

Prevalence at the three agro climatic zones

The prevalence of mange mite was 5.50\% (95\% Cl 5.1623-5.8589), 4.11\% (95\% $\mathrm{Cl} 3.8444-4.3794)$ and $2.17 \%(95 \% \mathrm{Cl} 1.7889-2.6127)$ in lowland, medium and highland agro climatic zones, respectively (Table 2 ). The difference was statistically significant $\left(X^{2}=112, P=0.0000\right)$. Odds ratio results indicated that animals in lowland were $1.36(\mathrm{OR}=1.36,95 \% \mathrm{Cl} O R$ 1.24-1.50), 2.63 times $(\mathrm{OR}=2.63$, $95 \% \mathrm{Cl}$ OR 2.15-3.20) more exposed than the high agro climatic zone.

Prevalence of mange mite in the three age group

Prevalence of goat mange mite was 3.31\% (95\% Cl 2.9593-3.6901) for age group of $<1$ year, $4.82 \%(95 \% \mathrm{Cl} 4.2985-5.3866)$ for $1-2$ year and $4.71 \%(95 \%$ 
Cl 4.4648-4.9675) for $>2$ year (Table 2). The difference was statistically significant $\left(X^{2}=35.56, P=0.0000\right)$.

Prevalence of mange mite in male and female

The prevalence of mange mite was $4.57 \%(95 \% \mathrm{Cl} 4.1735-4.9933)$ in male and $4.37 \%(95 \% \mathrm{Cl} 4.1559-4.5995)$ in female (Table 2). The difference was not statistically significant $\left(\mathrm{X}^{2}=0.71, \mathrm{P}=0.3978\right)$

Lice:

The biting lice Linognathus stenopsis (goat) and Linognathus ovillus (sheep) and the sucking lice, Damalina caprae (goat) and Damalina ovis (sheep) were the dominant species identified during the study. The overall prevalence of lice in the small ruminants was $6 \%(95 \% \mathrm{Cl} 5.7770-6.2266)$.(Table 3). At species level the prevalence was $0.37(95 \% \mathrm{Cl} 0.3001-0.4654)$ and $11.98 \%(95 \% \mathrm{Cl}$ 11.5466-12.4301) for sheep and goat, respectively (Table 3). According to this study goats were 36 times exposed more to lice infestation $(O R=36.07,95 \% \mathrm{Cl}$ OR 28.99-44.86) than sheep.

Seasonal prevalence of lice

The prevalence of lice infestation was $6.29 \%(95 \% \mathrm{Cl}$ 5.9707-6.6118) during dry season and $5.69 \%(95 \% \mathrm{Cl} 5.3840-6.0158)$ during wet season of the year (Table 3). Statistically significant difference $\left(X^{2}=6.72, P=0.0095\right)$ was observed between dry and wet season of the year. During dry season, animals were 2 times $(\mathrm{OR}=2.18,95 \% \mathrm{Cl}$ OR 1.51-1.77) at higher risk for contracting lice infestation than the wet season. 
Table 3: Prevalence of lice infestation in small ruminant in different season, agroclimate, age and sex

\begin{tabular}{|c|c|c|c|c|c|}
\hline & \multirow[t]{2}{*}{ Risk Factor } & \multirow{2}{*}{$\begin{array}{l}\text { Total Exam- } \\
\text { ined animals }\end{array}$} & \multicolumn{3}{|c|}{ Lice } \\
\hline & & & Positives & Negatives & Percent prevalence(\%) \\
\hline \multirow[t]{4}{*}{1} & $\begin{array}{l}\text { Animal spe- } \\
\text { cies }\end{array}$ & & & & \\
\hline & Sheep & 22,337 & 84 & 22,253 & 0.37 \\
\hline & Goat & 20,988 & 2,515 & 18,473 & 11.98 \\
\hline & Total & 43,325 & 2,599 & 40,726 & 5.99 \\
\hline \multirow[t]{4}{*}{2} & Season & & & & \\
\hline & Dry & 18,453 & 1404 & 20,933 & 6.29 \\
\hline & Wet & 24,872 & 1,195 & 19,793 & 5.69 \\
\hline & Total & 43,325 & & & \\
\hline \multirow[t]{5}{*}{3} & Agro- climate & & & & \\
\hline & Lowland & 16,755 & 1,154 & 15,601 & 6.89 \\
\hline & Medium & 21,507 & 1,255 & 20,252 & 5.84 \\
\hline & Highland & 5,063 & 190 & 4,873 & 3.75 \\
\hline & Total & 43,325 & & & \\
\hline \multirow[t]{5}{*}{4} & Age & & & & \\
\hline & $<1$ year & 9,486 & 682 & 8,804 & 7.19 \\
\hline & 1-2 year & 6,140 & 384 & 5,756 & 6.25 \\
\hline & $>2$ years & 27,699 & 1,533 & 26,166 & 5.53 \\
\hline & Total & 43,325 & & & \\
\hline \multirow[t]{4}{*}{5} & Sex & & & & \\
\hline & Male & 10,218 & 848 & 9,370 & 8.30 \\
\hline & Female & 33,107 & 1,751 & 31,356 & 5.29 \\
\hline & Total & 43,325 & & & \\
\hline
\end{tabular}

Prevalence lice at different agro climatic zones

The point prevalence of lice infestation in lowland, medium and highland agro climatic zones was 6.89\% $(95 \% \mathrm{Cl}$ 6.5086-7.2815), 5.84\% (95\% Cl 5.52576.1569) and $3.75 \%(95 \% \mathrm{Cl} 3.2462-4.3134)$, respectively (Table 3). The difference was statistically significant $\left(X^{2}=69.78, P=0.0000\right)$. Animals in the lowland were 2 times $(\mathrm{OR}=1.90,95 \% \mathrm{Cl}$ OR 1.62-2.22) more exposed to lice infestation than animals in the highland ago climatic zone.

Prevalence of lice infestation in the different age group

Lice infestation rate for the age group of $<1$ year, 1-2 year and $>3$ year were $7.19(95 \% \mathrm{Cl}$ 6.6777-7.7279), 6.25\% (95\% Cl 5.6612-6.8889) and $5.53 \%$ (95\% Cl 5.2681-5.8103), respectively (Table 3). The difference was statistically significant $\left(X^{2}=35.15, P=0.0000\right)$. Young animals $<1$ year age were 1.32 times at 
higher risk of acquiring lice infestation than animals $>2$ year age $(O R=1.32$, 95\% CI OR 1.20-1.45).

Prevalence of lice infestation in male and female goats

Prevalence of lice infestation was $8.30 \%(95 \% \mathrm{Cl} 7.7712-8.8508)$ in male and $5.28 \%(95 \% \mathrm{Cl} 5.0502-5.5355)$ in female animals. The difference was statistically significant $\left(X^{2}=121.27, P=0.0000\right.$ ) (Table 3 ). According to this study, male were 1.62 folds more susceptible to lice infestation than female $(O R=1.62,95 \%$ CI OR 1.49-1.79).

Sheep keds:

The Melophagus ovinus is the species of sheep keds identified. The over all prevalence of sheep keds in the study area was $11.67 \%(95 \% \mathrm{Cl} 11.2485$ 12.0950) (Table 4).

Sheep-Ked infestation rate in different agro climatic zones

The prevalence of sheep keds infestation in the lowland, medium and highland agro climatic zones were $1.84 \%(95 \% \mathrm{Cl} 1.5482-2.1732), 14.43 \%(95 \% \mathrm{Cl}$ 13.6882-15.1877) and $19.48 \%(95 \%$ Cl 18.5123-20.4794), respectively (Table 4). The difference was statistically significant $\left(X^{2}=1135, P=0.0000\right)$. According to this study, animals in the highland were around 13 times at higher risk of acquiring sheep ked infestation than the low altitude $(\mathrm{OR}=12.9,95 \% \mathrm{Cl}, \mathrm{OR}$ 10.77-15.44).

Sheep-Ked Prevalence in different age group

Point prevalence of $5.59 \%(95 \% \mathrm{Cl} 4.8198-6.4430), 12.57 \% \quad(95 \% \mathrm{Cl} 11.3378-$ 13.8844) and $12.7 \%(95 \% \mathrm{Cl} 12.1969-13.2205)$ were obtained during the study for age groups of $<1$ year, 1-2 years and $>2$ years, respectively (Table 4). The difference was statistically significant $\left(X^{2}=133.96, P=0.0000\right)$. Animals $>2$ years age were around 2.5 times exposed to sheep ked infestation than < 1 year age $(\mathrm{OR}=2.46,95 \% \mathrm{Cl}$ OR $2.10-2.88)$. 
Table 4: Prevalence of sheep keds of small ruminant in different season, agroclimate, age and sex

\begin{tabular}{|c|c|c|c|c|c|}
\hline & \multirow[t]{2}{*}{ Risk Factor } & \multirow{2}{*}{$\begin{array}{l}\text { Total Exam- } \\
\text { ined animals }\end{array}$} & \multicolumn{3}{|c|}{ Sheep Keds } \\
\hline & & & Positives & Negatives & $\%$ Positives \\
\hline \multirow[t]{4}{*}{1} & Animal species & & & & \\
\hline & Sheep & 22,337 & 2,606 & 19,731 & 11.67 \\
\hline & Goat & 20,988 & - & - & - \\
\hline & Total & 43,325 & & & \\
\hline \multirow[t]{5}{*}{2} & Agro- climate & & & & \\
\hline & Lowland & 16,755 & 137 & 7,303 & 1.84 \\
\hline & Medium & 21,507 & 1,236 & 7,332 & 14.43 \\
\hline & Highland & 5,063 & 1,233 & 5,096 & 19.48 \\
\hline & Total & 43,325 & & & \\
\hline \multirow[t]{5}{*}{3} & Age & & & & \\
\hline & $<1$ year & 9,486 & 179 & 3,023 & 5.59 \\
\hline & 1-2 year & 6,140 & 337 & 2,344 & 12.57 \\
\hline & $>2$ years & 27,699 & 2,090 & 14,364 & 12.70 \\
\hline & Total & 43,325 & & & \\
\hline \multirow[t]{4}{*}{4} & Sex & & & & \\
\hline & Male & 10,218 & 646 & 3,680 & 14.93 \\
\hline & Female & 33,107 & 1,960 & 16,051 & 10.88 \\
\hline & Total & 43,325 & & & \\
\hline
\end{tabular}

Sheep-ked prevalence in the two sexes

The prevalence of sheep keds was $14.93 \%(95 \% \mathrm{Cl} 13.8833-16.0302)$ in male and $10.88 \%(95 \% \mathrm{Cl} 10.4310-11.3461)$ in female (Table 4). The difference was statistically significant $\left(X^{2}=55.54, P=0.0000\right)$.

Physical condition of the examined animals

Out of the total positive animals for one of the external parasites, 2371 (91\%) were with poor physical condition, 209 (08\%) with moderate physical condition and $26(0.01 \%)$ with good physical condition.

\section{Discussion}

Generally our study showed that there is statistically significant difference in the prevalence of the external parasites between seasons, agro-climatic zones and animal species. Mange mite is one of the most important external parasites that down grade the value of skins in small ruminant. According to this 
study, there is difference in the susceptibility of mange mite infestation among the two species. Odds ratio analysis indicated that, goats were nine times more susceptible to mange mite infestation than sheep. This incidence might be associated with the dominant type of mange mite species in the study area which is sarcoptic mange mite. Sarcoptic mange mite affects more commonly goats than sheep. Of the mange mites affecting sheep and goat, Sarcoptes is the most prevalent species in Ethiopia (Sherman, 1998 and ESGPIP, 2009). Kahn (2005) also reported also that sarcoptic mange mite in sheep is very rare and if any, it is only seen in non-wooly areas.

In our study the prevalence of goat mange mite was $8.11 \%$. Different prevalence of goat mange mite have been reported from different parts of the country by various authors. Prevalence of $6.8 \%$ (Taddess, Zerihun, 1994) $3.96 \%$ (Mohammed Hussen, 2001) and 4.27\% (Worku Tadesse, 2002) have been reported from Eastern, Central and Southern parts of Ethiopia, respectively. In comparison with these studies, the present study showed relatively higher mange mite infestation rate than the rest of the country. This condition calls for special mange mite control intervention in the region for better skin quality and quantity production and to increase small ruminant productivity.

This study has also indicated that statistically significant difference was observed in the prevalence of mange mite between the lowland (5.5\%) and highland (2.17\%) agro climatic zones. Animals in lowland were 2.63 times more exposed to mange mite infestation than highland. In agreement with our findings many researchers reported the same results (Tefera Tserse, 2004 and Pangui, 1994). The high prevalence of the mange mite in the lowland may be associated with the ideal micro climate environment in these areas which favors the breeding and multiplication of mange mite eggs to their developmental stages (Pangui, 1994). High temperature, humidity and sunlight in the lowland favor mange infestation which account for the difference in the prevalence.

According to this study, mange mite prevalence was 1.67 times higher in the dry season of the year than the wet season. This condition might be associated with the shortage of feed and other environmental stress factors which are more common during the dry season. In agreement with this finding, Radostitis et al (2000) described that sarcoptic mange mite often-go hand in hand with poor feeding and general mismanagement.

This study showed difference in mange mite infestation among different age groups being higher in 1-2 years age group. Mukherjee and Dasgupta (2000) 
also reported higher prevalence of mange mite in young than the old age group.

Like that of mange mite, animals in the dry season also showed two fold risk of acquiring lice infestation than the wet season which may be associated with poor feed availability. In agreement with this study Tally (2007) described that animals under stress, poor condition and improperly fed carry heaviest lice infestation. The relative higher prevalence of lice during the dry period than the wet season, was not only associated with poor feed availability but may be related with the cool weather of the wet season, which had a negative impact on the breeding/lifecycle of the lice. Radostitis et al (2000) stated that wet condition shearing and reversing temperature gradients reduced lice population.

The present study showed that lice infestation was higher in animals $<1$ year age than $>2$ years age. Radostitis et al (2000) and Heath et al (1995) also reported similar findings that young animals are heavily infested and the number decrease as the animals mature. However, a cross sectional study conducted in Brazil by Santose and Faccini (1996) described that there was no statistically significant difference in the prevalence of the lice infestation between different age groups.

Another important external parasite of sheep is the sheep keds (Melophagus ovinus). Sheep keds suck blood and cause anemia as well as skin irritation that leads to a skin defect known as cockle or "Ekek" in Amharic. Cockle is a skin defect which appears on the grain side of semi-processed and crust leather after pickling that cannot be detected when the skin is examined raw or unprocessed. It results in huge economic loss to tanneries and the country at large since the damage is realized only after cost is incurred on processing after which the damaged skins have to be discarded or down graded (ESGPIP, 2000). The distribution of sheep keds was also higher in the highland than the lowland agro climatic zones. Sheep in the highland were 13 times exposed to ked infestation than the lowland and this knowledge on the spatial distribution of the parasites should be incorporated during the control program of the parasite. Analysis of seasonal population of sheep keds by Legg et al (1991) also indicated that ked population is mainly seen in colder, wetter areas and the infestation may be lost when the sheep are moved to hot dry district.

The economic impact of these external parasites is not only confined in downgrading the value of skins and hides, but also brings about significant body 
weight loss. According to this study, out of the total animals affected by the external parasites, $91 \%$ were at poor physical condition.

\section{Conclusion}

In the Tigray region the external parasites are treated with organophosphorous compounds such as Diazinon, however the treatment scheme is not supported by good epidemiological knowledge of the external parasites. This leads to poor quality and coverage of the service. Therefore to implement effective control strategy against the external parasites, good epidemiological knowledge on spatial and temporal distribution of the external parasites is of paramount importance. With this context, this study has generated important knowledge on the temporal and spatial distribution of the external parasites which may help as corner stone to propose and implement effective control strategy against the external parasites.

\section{Acknowledgments}

We would like to thank Ato Amdework Zekaryase, Ato Berhane Tsehaye and Ato Tsehaye Seyoum, members of the Mekelle Regional Veterinary Laboratory, for their technical support during collection and identification of specimens. We also thank Tigray Bureau of Agriculture and Natural Resource for its financial support.

\section{References}

Abadi, Y., 2000. Current problems of the leather industry. Ethiopian Tannery Association. Addis Abeba. Ethiopia.

Aiello, S. E and Mays A., 1998. The Merck Veterinary Manual, 8th Edition Merck and Co. Inc. White House Station, NJ, USA.

Ethiopia Sheep and Goat Productivity Improvement Program, ESGPIP, 2009. Common Defects of sheep/goat skins in Ethiopia and their causes. Technical Bulletin No. 19.

Epi Info version 3.5.1 for windows, 2008. A word-processing, data base and statistics program for public health on IBM-compatible microcomputers. World Health Organization (WHO), Geneva, Switzerland. 
FAO, 2001. Control of sheep and goat skin diseases for improvement quality of hides and skins -Phase I and II, Ethiopia. Terminal statement prepared for Government of Ethiopia. Technical cooperation program. Rome.

Heath, A. C., Cooper, S. M., Cole, D. J. and Bishop, D. M., 1995. Evidence for the role of the sheep-biting louse Bovicola ovis in producing cockle, a sheep pelt dept. Veterinary Parasitology 59: 53-58.

Hussen, M., 2001. Study on skin diseases of small ruminant in central Ethiopia, DVM thesis, FVM, Addis Abeba University, Debre Zeit.

Kahn, G. M., 2005. The Merck Veterinary Manual. Merck and Co. Inc. White house station, N. J., USA.

Legg, D. E., Kumar, R., Watson, D. and Llooyd, J. E., 1991. Seasonal movement and spatial distribution of sheep keds (Diptera: Hippoboscidae) on Wyoming lambs. Journal Economic Entomology.

Mukherjee, B. and Dasqupta, C. K., 2000. The prevalence of sarcoptic mange mite in goat of Birbhum area of West Bengal. Journal of research 12: pp. 135 - 137. Birsa Agricultural University.

Pangui, L. J., 1994. Mange mite in domestic animals and methods of control. Rev. Sci. Tech. Off. Int. Epi., 13 (4), pp 1227-1243.

Radostitis, O. M., Gay, C. C., Blood, D. C., Hinchcliff, K. W., 2000. Veterinary Medicine. A text book of the diseases of cattle, sheep, pig and horse, 9 th edition.

Santos, A. C. and Faccini, J. L. H., 1996. A cross -sectional study of louse infestation caused by Damalina caprae (trichodectde mallapho) in semi arid regional of the state of Paraiba. Rivista Brazilia de parasitologia veterinaria (Brazil) 5: pp 4346.

Sertse, T., 2004. Investigation on ectoparasites of small ruminants in selected sites of Amhara regional state and their impact on the tanning industry. MSc thesis, FVM, Addis Abeba University, Debre Zeit. Addis Abeba.

Sherman, M. D., 1998. Diagnosis of major skin diseases of sheep and goat. In: Proceedings of control of sheep and goat diseases for improvement quality of skins and hides, 13-14 Feb. 1998, Addis Abeba, Edited by lan, B.C and Bayou, K. FAO, Addis Abeba. 
Taddess, W., 2002. Study on small ruminants skin disease in Sidama Zone. DVM thesis, FVM, Addis Abeba University, Debre Zeit

Talley, J., 2007. External parasites of goats. Pp 76-80 in Proceedings 22nd Annual Goat field day, Langston University, Langston, USA.

Tigray Bureau of Agriculture and Natural Resource Development/TBANRD, 1999: Livestock census analysis result, Mekelle, Tigray, Ethiopia.

Urquhart, G. M., Duncan, J. L., Dunn, A. M., Jennings, F. W. Frank and Jennings, W., 1996. Veterinary Parasitology. University of Glasscow. 2nd Edition.

Zerihun, T., 1994. Survey of mange mite and ticks of camel and small ruminats in Dire Dawa region. DVM thesis, FVM, Addis Abeba University, Debre Zeit. 